\title{
Technological factors influence on the work efficiency of the feed grinder
}

\author{
Ibrahim M. Gomaa, Ildar I. Kashapov, Ramil R. Khaidarov, Rais F. Sabirov*, and Farida F. Khasanova \\ Kazan State Agrarian University, 420015 Kazan, Russia
}

\begin{abstract}
The article discusses the factors affecting the reduction of the energy consumption of feed chopping and the justification of the feed chopper parameters. There is a design and principle of operation of the laboratory setup presented and described. A corn cob chopper with improved chopping quality reduces energy consumption, lowers operating costs and improves feed digestibility.
\end{abstract}

\section{Introduction}

The grinding process in feed preparation accounts for up to $60 \%$ of all energy costs, which in turn makes up $50 \%$ of the total economic cost of preparing feed [1-3]. Thus, in connection with the development of small farms in the Republic of Tatarstan that do not have large energy capacities, the need arises to develop an energy-saving, small-sized and highly efficient feed chopper.

All types of feed (roughage, leguminous, green mass, corncobs, root tubers, etc.), before being fed to animals, undergo the grinding process. For this, various types of food choppers are used [4-9].

Grinding is the process of separating a solid particle mechanically by applying external forces that are much greater than the strength of molecular cohesion. The grinding process is subjected to grain cereals, legumes, oilseeds, as well as chalk, salt, roughage, root crops, etc.

As a result of grinding, animal energy costs for chewing feed are reduced, the assimilation of nutrients by the animal's body is improved, and friability of feeds is increased, which allows better mixing of feed and improving the conditions of mechanization of dosing and distribution processes.

The production of animal feed for different types of animals requires various grain mills. The grinding module for cattle requires grain size $1.8-2.6 \mathrm{~mm}$. Such crushed grain is better processed by the gastric juice of the animal and may be absorbed completely.

If the grinding is too fine, the dusty particles stick together and form lumps in the stomach, leading to the gastric juice penetrates and as a result the food is not absorbed.

There are various ways to grind feed. The most commonly used methods are breaking with a free blow (using a hammer mill), crushing (on a roller conditioner), chipping or crumbling.

Each of the grinding methods is applicable for certain types of feed, depending on their physical and mechanical properties and the purpose of grinding [10$13]$.

\section{Materials and methods}

According to the analysis of previous studies, the factors mainly affect the efficiency of the choppers are [14]:

1. Humidity chopping feed;

2. The rotation frequency of the grinding working bodies;

3 . The degree of grinding of feed;

4. The grinding time.

The feed chopper under development (Figure 1) contains a frame 4 , a vertical chamber 2 with knives. A shaft 5 is mounted inside the chamber with knives 6 and spatula 3 fixed on it. Feed through the pipe 1 enters the cutting chamber 2, where it is crushed by knives 6 fixed on the shaft 5. The crushed feed enters the lower part of the housing, where it is carried out through the unloading under the action of the blades branch pipe.

Reducing energy costs for grinding feed can only be achieved by changing the design parameters of the grinder. One of these parameters are: knife blade thickness, sharpening angle, etc.

The thickness of the knife influences the grinding process. Cutting knives (Figure 1) are made of durable steel, $3 \mathrm{~mm}$ thick in the amount of 9 pieces. To evenly distribute the load on the knives and improve the chopping quality, the distance between the knives is reduced from top to bottom.

The main attention in the study is paid to changes in four main factors: the degree of grinding, moisture of the ears of corn, rotational speed and grinding time.

The moisture of the corn cobs is determined in the following order. About $300 \mathrm{~g}$ of the test sample is placed in a separate container with portions weighing $50 \mathrm{~g}$ taken and placed in boxes. In each box you need to place exactly $50 \mathrm{~g}$ of chopped feed.

The drying cabinet is preheated up to a temperature of $140{ }^{\circ} \mathrm{C}$ and the boxes are placed in a drying cabinet,

\footnotetext{
* Corresponding author: agromehanika116@gmail.com
} 
being kept for 40 minutes at a temperature of $130{ }^{\circ} \mathrm{C}$. After time, the boxes are removed from the cabinet, closed with lids and cooled for 15-20 minutes.
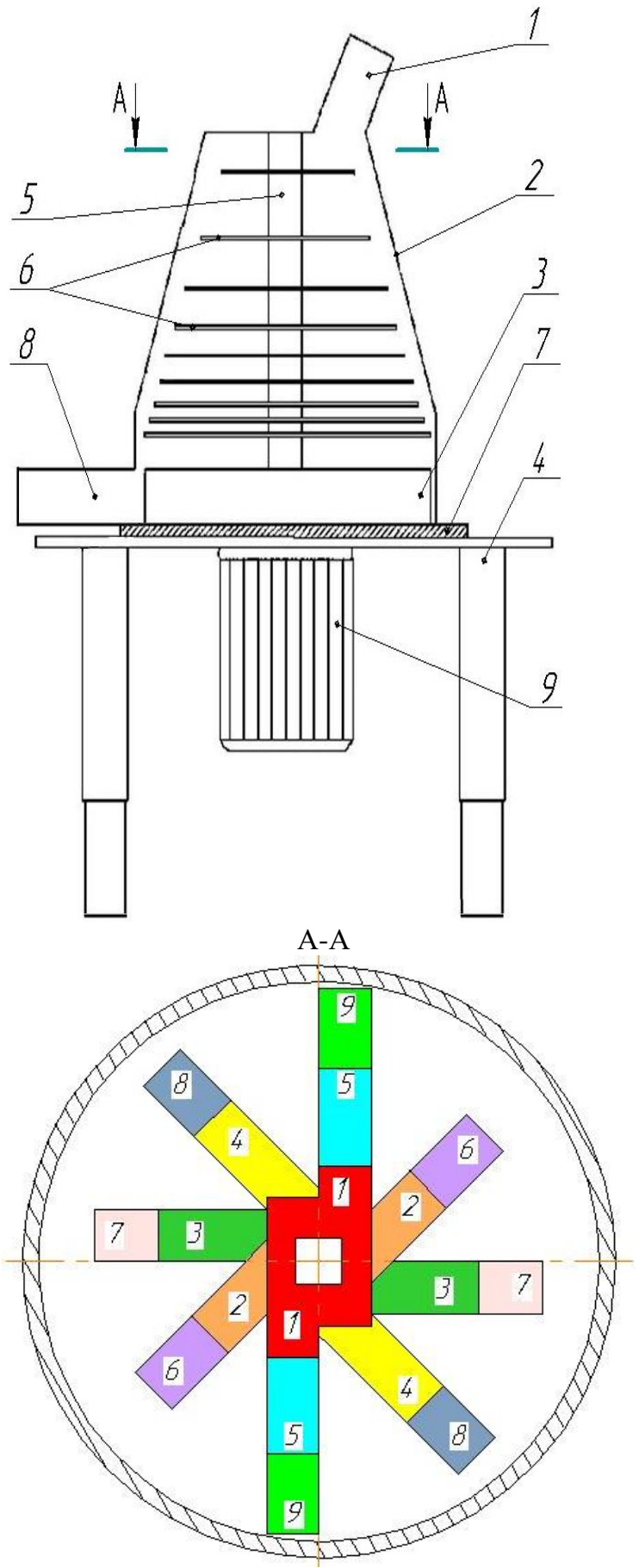

Fig. 1. General view of the feed chopper being developed: $1-$ inlet pipe; 2 - cutting case; 3 - scapula; 4 - frame; 5 - shaft; 6 - knives; 7 - rubber sealant; 8 - discharge pipe; 9 - electric motor.

\section{Results}

The authors of this article conducted experiments to determine the effect of rotation speed and moisture of the crushed feed on the grinding time, productivity and the degree of grinding.

The experiments were conducted on a manufactured laboratory setup for grinding feed. The frequency of rotation of the blade rotor varied within $600,900,1200$ and $1500 \mathrm{~min}^{-1}$. There were corn cobs with a moisture content of $\mathrm{W}=33$ and $66 \%$ prepared.

The results of the experiments were processed in Microsoft Office Excel 2007, with the help of which the data were obtained which are presented in tables $1,2,3$, 4 and in the form of graphs.

Table 1. Dependence of feed grinding time on rotation speed and feed moisture

\begin{tabular}{|c|c|c|c|c|}
\hline \multirow{2}{*}{ Humidity, \% } & \multicolumn{4}{|c|}{ Grinding time, $\mathrm{s}$} \\
\cline { 2 - 5 } & \multicolumn{4}{|c|}{ Rotation speed, min $^{-1}$} \\
\cline { 2 - 5 } & 600 & 900 & 1200 & 1500 \\
\hline 33 & 10.6 & 8.9 & 7.6 & 6.4 \\
\hline 66 & 11.6 & 9.4 & 8.2 & 6.8 \\
\hline
\end{tabular}

According to the graph, regardless of the moisture content of the feed ground, the grinding time decreases with an increase in the rotational speed of the grinding rotor.

The graph shows, the productivity of the grinder increases due to the increase in the speed of rotation of the grinding rotor.

Table 2. The dependence of the grinder on the speed of feed rotation and humidity

\begin{tabular}{|c|c|c|c|c|}
\hline \multirow{2}{*}{ Humidity, \% } & \multicolumn{4}{|c|}{ Productivity, $\mathrm{kg} / \mathrm{h}$} \\
\cline { 2 - 5 } & \multicolumn{4}{|c|}{ Rotation speed, $\mathrm{min}^{-1}$} \\
\cline { 2 - 5 } & 600 & 900 & 1200 & 1500 \\
\hline 33 & 50.9 & 60.6 & 70.5 & 84.1 \\
\hline 66 & 46.5 & 57.2 & 65.8 & 79.2 \\
\hline
\end{tabular}

Table 3. The dependence of the degree of feed grinding on the speed of rotation at a moisture content of $33 \%$

\begin{tabular}{||c|c|c|c|c|c|}
\hline \multirow{3}{*}{ Humidity, \% } & \multicolumn{5}{|c|}{ The degree of grinding, \% } \\
\cline { 2 - 6 } $\begin{array}{c}\text { The sizes of } \\
\text { the crushed } \\
\text { particles }\end{array}$ & 600 & 900 & 1200 & 1500 \\
\cline { 2 - 6 } & $\geq \varnothing 8 \mathrm{~mm}$ & 16.8 & 17.6 & 18.1 & 14.7 \\
\hline & $\geq \varnothing 7 \mathrm{~mm}$ & 49.7 & 34.8 & 32.6 & 18.4 \\
\cline { 2 - 6 } & $\geq \varnothing 6 \mathrm{~mm}$ & 29.7 & 38.8 & 26.1 & 27.2 \\
\cline { 2 - 6 } 33 & $\geq \varnothing 5 \mathrm{~mm}$ & 1.65 & 3.7 & 9.5 & 14.5 \\
\cline { 2 - 6 } & $\geq \varnothing 4 \mathrm{~mm}$ & 0.9 & 1.92 & 4.6 & 5.9 \\
\cline { 2 - 6 } & $\geq \varnothing 3 \mathrm{~mm}$ & 0.54 & 1.58 & 3.1 & 6.8 \\
\cline { 2 - 6 } & $\geq \varnothing 2 \mathrm{~mm}$ & 0.25 & 0.98 & 3.8 & 5.7 \\
\cline { 2 - 6 } & $\geq \varnothing 1 \mathrm{~mm}$ & 0.46 & 0.62 & 2.2 & 6.8 \\
\hline
\end{tabular}




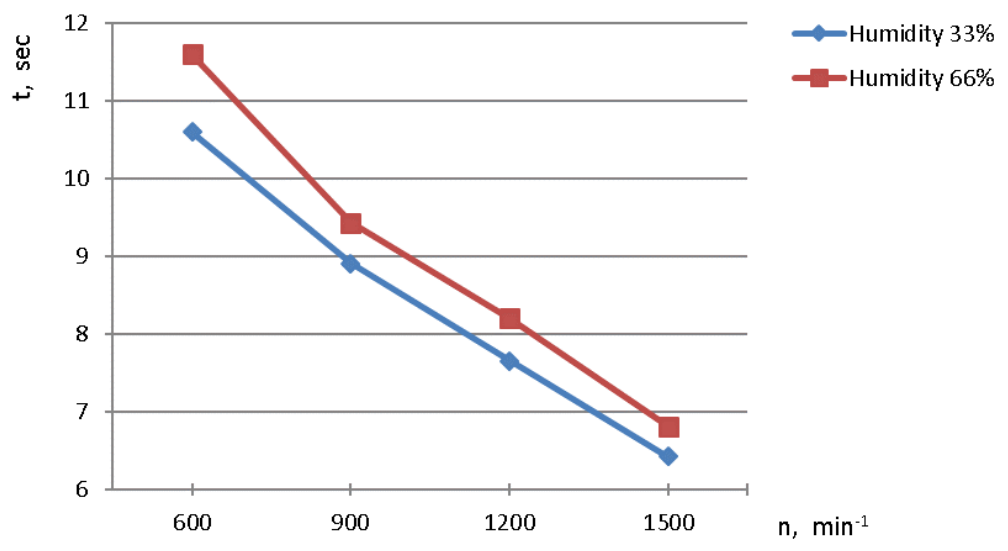

Fig. 2. Graph of feed grinding time versus rotational speed and feed moisture

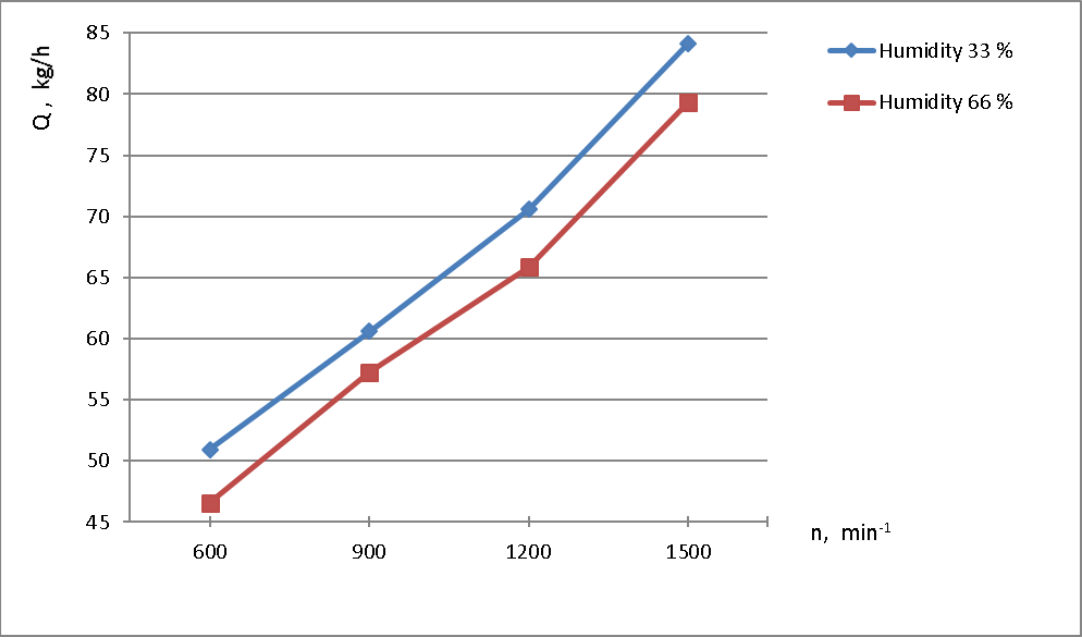

Fig. 3. A graph of the chopper performance versus rotational speed and feed moisture

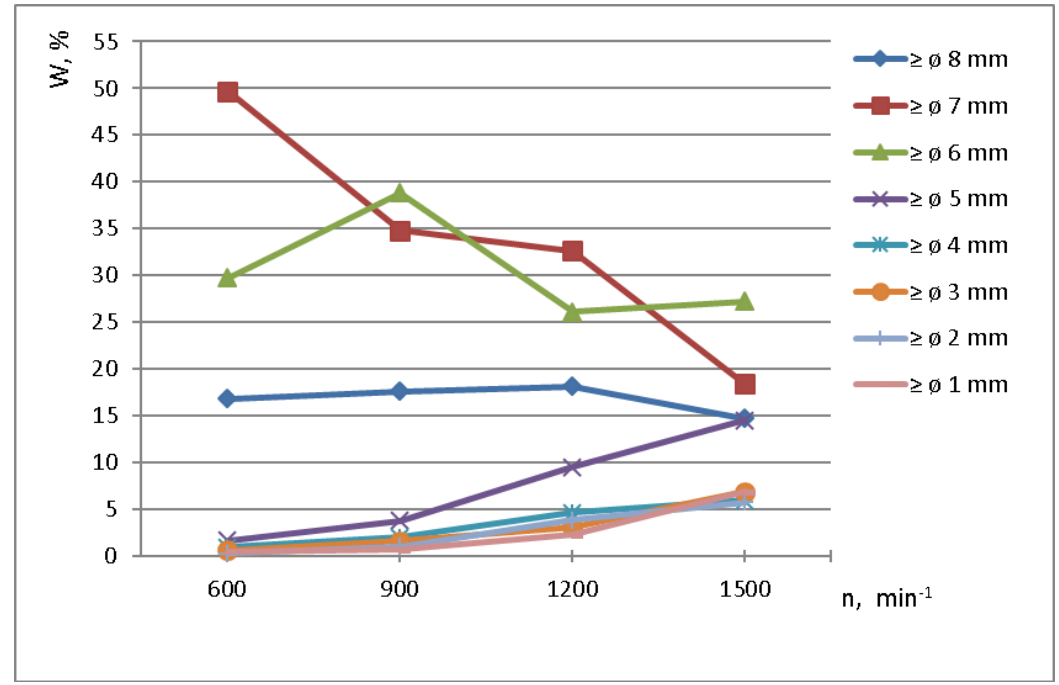

Fig. 4. The dependence of the degree of feed grinding on the rotation speed at a moisture content of $33 \%$ 


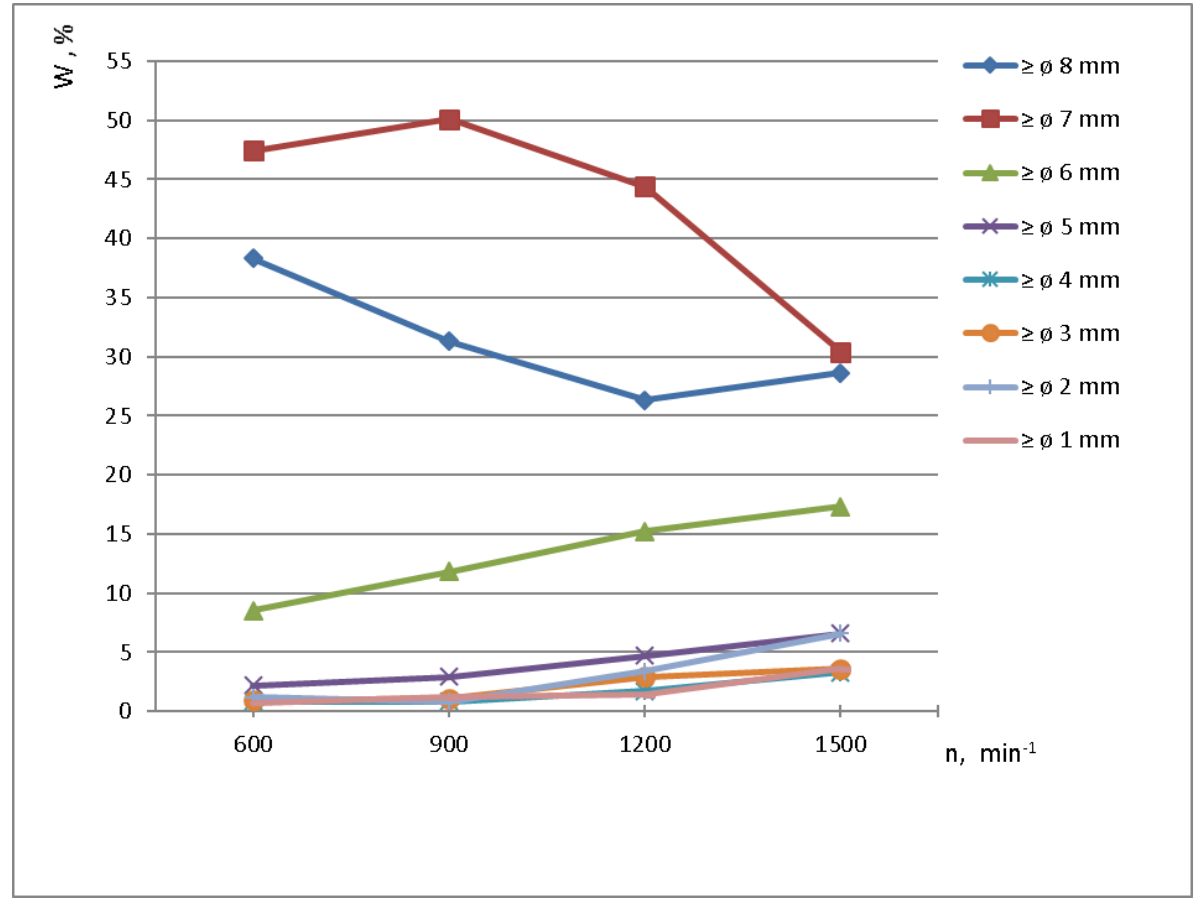

Fig. 5. The dependence of the degree of feed grinding on the rotation speed at a humidity of $66 \%$

Table 4. The dependence of the degree of grinding of feed on the rotation speed at a humidity of $66 \%$

\begin{tabular}{|c|c|c|c|c|c|}
\hline \multirow{3}{*}{$\begin{array}{c}\text { Humidity } \\
\%\end{array}$} & \multicolumn{5}{|c|}{ The degree of grinding, $\%$} \\
\hline & \multirow{2}{*}{$\begin{array}{l}\text { The sizes } \\
\text { of the } \\
\text { crushed } \\
\text { particles }\end{array}$} & \multicolumn{4}{|c|}{ Rotation speed, $\min ^{-1}$} \\
\hline & & 600 & 900 & 1200 & 1500 \\
\hline \multirow{8}{*}{66} & $\geq \varnothing 8 \mathrm{~mm}$ & 38.3 & 31.3 & 26.3 & 28.6 \\
\hline & $\geq \varnothing 7 \mathrm{~mm}$ & 47.4 & 50.1 & 44.4 & 30.4 \\
\hline & $\geq \varnothing 6 \mathrm{~mm}$ & 8.5 & 11.8 & 15.2 & 17.3 \\
\hline & $\geq \varnothing 5 \mathrm{~mm}$ & 2.2 & 2.9 & 4.7 & 6.7 \\
\hline & $\geq \varnothing 4 \mathrm{~mm}$ & 0.8 & 0.8 & 1.7 & 3.3 \\
\hline & $\geq ø 3 \mathrm{~mm}$ & 0.9 & 1.1 & 2.9 & 3.7 \\
\hline & $\geq \varnothing 2 \mathrm{~mm}$ & 1.2 & 0.8 & 3.4 & 6.5 \\
\hline & $\geq \varnothing 1 \mathrm{~mm}$ & 0.7 & 1.2 & 1.4 & 3.5 \\
\hline
\end{tabular}

\section{Conclusion}

1. According to the results of experimental studies, the bulk of the crushed feed has a particle size of more than $5 \mathrm{~mm}$. This condition is unsatisfactory.

2. Based on this, in order to reduce the degree of feed grinding, there is a need to install 3 additional knives for each mixing blade.

\section{References}

1. B.G. Ziganshin, Improving the efficiency of technical means of preparing feed in animal husbandry based on expanding the technological capabilities of choppers, PhD dissertation (Kazan, 2004)

2. B.G. Ziganshin, New technical means for grinding feed, Dairy and beef cattle breeding, 8, 16 (2004)
3. D.I. Fayzrakhmanov, F.T. Nezhmetdinova, B.G. Ziganshin, A.R. Valiev, Food safety in the WTO, Rural mechanic, 11(57), 4-6 (2013)

4. I.I. Kashapov, Energy-saving technologies in agriculture, in proc. of the VI int. sci. and practi. conf. Actual problems of energy of agriculture, 8890 (Tsesain, Saratov, 2015)

5. N.M. Koshkare, Installation for preparative ration of feed mixtures, Patent no. 2272401 RU. - Publ. 03/27/2006. Bull. no. 9.

6. K.A. Vladimirovich, P.V. Ivanovich, Crusher feed, Patent no. 2019953 RU. - Publ. 09/30/1994.

7. V.V. Shevtsov, E.I. Reznik, P.A. Savinykh, Twostage crusher feed, Patent no. 2193839 RU. - Publ. 12/10/2002. Bull. no. 34 .

8. B.G. Ziganshin, I.E. Volkov, R.R. Khaidarov, I.F. Fayzullin, Universal shredder feed. Patent no. 2296011 RU. Publ. 03/27/2007. Bull. no. 9.

9. R.R. Khaidarov, B.G. Ziganshin, Universal shredder of root tubers IKH-5.5, Bull. of Kazan state agrar. Univer., 7(1(23)), 109-111 (2012)

10. B.G. Ziganshin, Technologies and technical means of preparation of feeds (Publishing house of Kazan University, Kazan, 2003)

11. B.G. Ziganshin, A.R. Valiev, N.N. Khamidullin, Some problems of technical support of agriculture and prospects of its development, Bull. of Kazan state agrarian Univer., 3(2(8)), 148-152 (2008)

12. B.G. Ziganshin, A.V. Dmitriev, A.R. Valiev et al., Forage harvesting machines (Machines for fodder), Textbook, 2rd ed. (LAN, St. Petersburg, 2016)

13. B.G. Ziganshin, R.R. Lukmanov, R.R. Gainutdinov, Energy-saving technical means in dairy farming, in 
Mater. digest of the XXVIII Int. Res. and Pract. Conf., 74-75 (Published by IASHE, London, 2012)
14. R.R. Khaidarov, B.G. Ziganshin, Assessment of the quality of chopping root crops, Bull. of Kazan state agrar. Univer., 8(1(27)), 84-87 (2013) 